\title{
Trench work: Scaffolding a metaphorical bridge to foster the advancement of caring sciences
}

\author{
Colleen Maykut * Meredith Porter \\ MacEwan University, Edmonton, Canada
}

Received: September 17, 2014

Accepted: September 23, $2014 \quad$ Online Published: April 18, 2015

DOI: $10.5430 / \mathrm{cns} . v 3 \mathrm{n} 3 \mathrm{p} 44$

URL: http://dx.doi.org/10.5430/cns.v3n3p44

\begin{abstract}
Caring, as knowledge, must be foundational within a nursing curriculum; while caring, as action, must be consistently nurtured in caring relationships to foster healing environments. If caring is seen as a way of being that emanates from a nurse's expression of their humanity then knowledge of caring sciences is vital in nursing education to ensure the development of an ethical, epistemological, and ontological perspective for both educators and students. One approach to ensuring the actualization of a caring science curriculum is through authentic dialogue, thereby, embodying the prerequisites necessary for a nursing student to espouse a caring practice is imperative. A novel approach to curriculum development evolved following a candid discussion between nursing students and faculty with respect to a core course offered in an undergraduate nursing program. This discussion inspired the co-development of case studies grounded in the caring sciences exploring the concepts of moral dilemmas, spirituality, and suffering. As nursing faculty, we have the opportunity and responsibility to create and role-model caring relationships with our students to enhance their future nursing practice and to continue to nurture our own professional development; influencing knowing, doing, and being as a caring practitioner. The authors, an enrolled undergraduate nursing student (during the research study) and a tenured faculty member, will reflect on their journey of scaffolding a metaphorical bridge (initiating, developing, and sustaining an innovative academic collaboration) grounded in caring sciences to enhance undergraduate nursing education.
\end{abstract}

Key Words: Caring, Curriculum, Collaboration, Mentorship, Reflection, Relational practice

\section{INTRODUCTION}

Caring is the essence of nursing practice; providing the necessary foundational knowledge (ethical, epistemological, and ontological paradigms) to espouse caring attributes towards others and one's self by appreciating our lived experiences. ${ }^{[1-3]}$ Caring, as knowledge, must be foundational as nursing curriculum; while caring, as action, must be consistently nurtured in caring relationships to foster healing environments. A caring relationship and a healing environment offer a context to support the development and growth of the other and of one's self. ${ }^{[3]}$ As nursing faculty, we have the opportunity and responsibility to create and role-model caring relationships with our students to enhance their future nursing practice ${ }^{[4]}$ and to continue to nurture our own professional development; influencing knowing, doing, and being as a caring practitioner. Nursing is a practice discipline and therefore, reflection on acquired attributes, skills, and knowledge is vital to ensure safe, competent, and ethical nursing practice while enhancing the professional development and growth of the caring nurse. ${ }^{[5]}$

Self-reflection is a necessary skill in nursing practice requiring both development and refinement to enable the

\footnotetext{
*Correspondence: Colleen Maykut; Email: maykutc@macewan.ca; Address: MacEwan University, 9-507G, 10700-104 Avenue, Edmonton, Alberta, T5J 4S2 Canada.
} 
nurse/nursing student to understand the relevance and applicability of the current experience to transform their future practice. ${ }^{[2]}$ Therefore, self-reflection in nursing education must not only be taught to nursing students but must be role-modelled by faculty. Facilitating reflection on concrete experiences and abstract concepts may foster connotative learning: the capacity to understand, act, decide and commit. ${ }^{[6]}$ Learning is not limited to outcomes but should include appreciation of the process which may promote the creation of shared knowledge. Literature on nursing students enhancing peer-to-peer learning in undergraduate education as a strategy to enhance cooperative and cognitive learning in lab, clinical, and simulation settings exists as outcome and process. ${ }^{[7]}$ However, there is an absence of literature regarding an undergraduate nursing student and faculty collaboration, with respect to enhancing learning through curriculum development, as both process and outcome. The authors, an enrolled undergraduate nursing student (during the research study) and a tenured faculty member, will reflect on their journey of scaffolding a metaphorical bridge (initiating, developing, and sustaining an innovative academic collaboration) grounded in caring sciences to enhance undergraduate nursing education. The acquisition of insights into the experiences of scaffolding through the development of an innovative academic collaboration (IAC) will provide the reader an opportunity to discover the richness of this relationship and its importance in nursing education.

\section{SCAFFOLDING THE METAPHORICAL BRID- GE}

\subsection{Initiating the collaboration}

There were three objectives of the research study where the IAC was initiated. The first objective was to examine the effectiveness of utilizing a combined teaching strategy of a vodcast and case study in a theory course to enhance acquisition of caring knowledge to inform clinical practice. The second was to determine the effectiveness of an IAC between nursing faculty and research assistants (enrolled nursing students in the BScN program) who have successfully taken the nursing course, to assist with development of case studies to facilitate a content and context perspective. The final objective was to explore how reflection as a tool shapes current and future learning experiences and teaching performances.

While attending the IAHC conference in Florida in 2013, a group of MacEwan students and faculty including these writers were able to discuss and consider the ideas of mentorship and collaboration with respect to both workplace and educational scenarios. This ability to have frank conversations shaped the nature of the dialogue that occurred during and after the conference. Students were able to share vignettes of their own first experiences in clinical practice, many of which were far from the idealized notions that were presented and promoted within the nursing school environment. The students spoke of intimidation of patients, the nursing students themselves, as well as other professionals within the health care environment. There were themes that emerged within these discussions: uncaring behaviors within caring environments, alienation of patients from the health care team, powerlessness and moral distress, estrangement and "turning away" from caring in nursing. Faculty members were able to share their own experiences of entering nursing practice as novices and persisting, despite the many challenges. Faculty members and students were able to influence anothers' experiences and to prompt individual self-reflection through the joint investigation of these experiences. This degree of engagement on the part of faculty as well as then-students prompted consideration of the nature of teacher-student relationships and how they might shape professional development after transitioning from the idealized nursing utopia into every day practice. This telling of stories led into intimate conversations about the meaning of nursing and caring alongside exposing vulnerabilities of novice practitioners encountering distressing scenarios in workplace environments. By peeling back the "layers of meaning" within these encounters, the students as well as the instructors were able to co-create significant meaning for reflection as well as future learning opportunities.

The healthcare and the university environment both promote an individual pursuit of practice and learning which can lead to isolation of health professionals, educators and students. ${ }^{[8]}$ This isolation promotes alienation and vulnerability when attempting to make meaning out of difficult or challenging circumstances. $^{[2]}$ Creating educational approaches which reinforce hierarchical power differentials through structures of "expert" (educator) and "learner" (student), promotes the continuation of these power structures into clinical practice as students leave education and enter the clinical environment. Adoption of this particular educational approach can widen and create a metaphorical "trench" between shared experiences, preventing the co-creation of new and significant meaning (and therefore learning) from being explored and developed. Therefore, the novel approach of co-developing case studies for introduction into a core course, where the material required personal investment in the concepts of Suffering and Caring Science, initial scaffolding on a bridge was begun over the trench to allow for safe passage of both faculty and nursing students. For the novice nursing students, the ability to discuss these case studies in the safety of a peer-led group rather than through a traditional instructor/professor led dialogue was an attempt to build a bridge for 
those students across the trench of inexperience and the risk of self-exploration/self-exposure about particularly valueladen subjects that would reflect directly on their own developing understanding and knowledge of nursing and caring science.

How can professors in traditional learning environments find students who are willing and able to maintain the balance of a dual role relationship whilst still enrolled in a nursing program? Throughout this process, it became clear that finding like-minded people to develop the project and case studies was essential, and yet one of the most challenging aspects of developing such a project. It further became apparent the need for students to possess a variety of rich life experiences, personal investment in intellectual discourse prior to participating in the project, and willingness to commit to actualizing the various stages of the project. Elements of a relationship of this nature must include significant trust and respect between all parties. This will attempt to mitigate the potential interference of power differentials from changing the nature of the relationship from structures of "expert" (educator) and "learner" (student) to colleagues.

Further, there is a need to build a trusting relationship between the experienced students and novice students within a very brief classroom exposure setting to allow for meaningful facilitation and discussion of the core course materials. Consideration of power dynamics and influence needs to be addressed within these relationships as well. Levelling off the relationship structures will allow for meaningful mutual self-reflection informed by the unique perspectives of another throughout the development of the collegial relationship. This both challenges and further defines the lived experiences of the students and the faculty members involved in the collaboration/relationship. This collectively informed self-inquiry is a critical component of reflective practice that guides promotes and develops practitioner knowledge and expertise over time.

\subsection{Developing the collaboration: Andragogical design}

As previously stated, knowledge of caring must be integrated into nursing curriculum. If caring is seen as a way of being that emanates from a nurse's expression of their humanity then knowledge of caring sciences is vital in nursing education to ensure the development of an ethical, epistemological, and ontological perspective for both the educator and nursing student. A nursing curriculum grounded in a caring paradigm offers a worldview that challenges our assumptions of "What it means to be caring?" This way of understanding and living our humanity facilitates a deep appreciation for nursing praxis and caring for one's self. "Praxis is a synthesis of thoughtful reflection, caring, and action within a theory and research-driven practice" ${ }^{[9]}$ which provides an insightful lived experience of our nursing life. Nursing praxis is NOT innate and must be introduced and nurtured during a nursing student's formational years. Nursing education, however, continues to place great emphasis on the psychomotor and cognitive domains while diminishing the importance of internalizing and expressing intentional actions grounded in caring. ${ }^{[8]}$ A caring science curriculum enables the expression of all domains to foster the development of a caring practitioner by creating a safe milieu for caring practices to be expressed. This transformation way of learning is best expressed by Hills and Watson ${ }^{[10]}$ “.... think about the discipline of nursing as an integration of artistry within an expanded view of science. Once one places the human and caring into a model of science, the model evolves, congruent with the timeless history, heritage, traditions, and practices of nursing". One approach to ensuring the actualization of a caring science curriculum is through authentic dialogue, ${ }^{[10]}$ thereby, understanding the prerequisites necessary for a nursing student to espouse a caring practice is imperative.

\subsubsection{Design of class}

Elements of a caring science curriculum were integrated into a "flipped classroom" or "take the professor home" approach to engage students in the acquisition and expression of caring knowledge to inform their future clinical practicums. This andragogical approach included review of three peer-reviewed articles (content reflected: a spiritual assessment tool; the lived experience of suffering; and finally Roach's 6 Cs of Caring) and a faculty created vodcast prior to class. The class was a third year theory course introducing concepts not limited to: care for the acutely ill across the lifespan, caring and healing, as well as relational practice. The vodcast was a pre-requisite learning strategy (to introduce new content as well as integrate previously acquired knowledge) in preparation for a case study format in the classroom which offers students all three modes of learning: kinesthetic, visual, and auditory. ${ }^{[11,12]}$

Vodcasts have the ability to capture the learning moment through auditory and visual (slides, videos, photographs, and other images) and offer the opportunity for repetition of content to enhance knowledge retention for the student. ${ }^{[13]}$ The vodcast content included: theoretical concepts of caring sciences, suffering, spiritual assessment, and self-care for the nurse. Knowledge retention is also improved when grounded in a narrative pedagogical approach. ${ }^{[14]}$ Therefore, case studies were developed to serve as a teaching and learning strategy to translate theoretical knowledge (peer-reviewed articles and content from the vodcast) into clinical practice in a safe environment. Case studies as an experiential learning experience $^{[15-17]}$ provide an opportunity to mimic real-world 
practice by articulating underlying principles of safe, competent, and ethical nursing practice (developing a critical thinking pathway) which is one of the main premises of introducing case studies as a teaching and learning strategy in nursing education. ${ }^{[17]}$ These strategies may address the struggle between the enormity of content required and the application of this knowledge to facilitate transformational learning for the nursing student's current clinical practicums and future nursing practice.

\subsubsection{Content: Caring sciences, moral dilemmas, spiritu- ality, and suffering}

Transformational learning is an outcome of a caring science curriculum utilizing a narrative pedagogical approach; incorporating multiple ways of knowing which focus on critical inquiry to enhance knowledge necessary for safe, ethical, and competent clinical practice. Narratives or story-telling may help to develop competence in the learner when utilized as a learning strategy. ${ }^{[18,19]}$ Two case studies were created in dialogue between the co-researchers and nursing faculty. This collaboration utilized both the co-researcher's context perspective (the lived experience of a fourth year nursing student's paid employment) and faculty as content and context experts to ensure a theoretical, scholarly, and realistic development of case studies which would engage the nursing student and inform their future practice. Guided questions were also developed to enhance the critical thinking and application of the content for the nursing student.

The first case study focused on a moral dilemma experienced by one of the co-researchers and introduced the concept of suffering viewed through the lens of conscience. ${ }^{[1]}$ The suffering was from the viewpoint of a nursing student who struggled within her scope of practice while being unduly influenced by the power dynamic of the interdisciplinary team to ensure ethical nursing care. The premise of the guiding questions was to evoke discussion amongst the students, facilitated by the co-researchers, dilemmas surrounding vulnerability from the patient and the nursing student perspective, breach of conscience, dehumanization of patients in care, and nursing actions to diminish suffering. The second case study examined spirituality through the lens of compassion and competence. ${ }^{11]}$ A family experiencing a young child's devastating diagnosis was the context in which to explore spirituality. Guiding questions elicited discussion on: defining spirituality, recognizing spiritual distress, and nursing actions to promote spirituality in which to enhance healing.

Academically the end result is the development of co-created case studies with integration into core curriculum to enhance student learning to facilitate transition into clinical practice. However, the meaning each researcher derives from their own lived experience within the project itself has influenced the others, therefore the sum of the parts is greater than the end result of the project. This is the essence of why the project was initiated. Co-creating new meaning expands and informs nursing education and clinical practice which helps to provide a model for collaborative relationships for future consideration.

\subsection{Sustaining the relationship}

\subsubsection{Co-Researcher (Meredith)}

The educational triad (nursing faculty, co-researcher, and nursing student) within the project described above might have application for the novice clinical practitioner. My own interest within this project was exploring how studentcentered projects such as this one might lead to more patientcentered care within an acute health care setting, upon which professional relationships might be influenced and shaped to include more collaborative approaches to care. Perhaps the notion of a clinical triad (Physician/Nurse Practitioner, Registered Nurse, and Patient) could be an equally effective in building bridges, facilitating trusting relationships among all parties, and ensuring collaborative outcomes are actualized. This would be an ideal approach to ensure high-quality, patient-centered care.

This project provided an opportunity to explore the idea of these constructs as an approach that could be adopted by the co-researcher who is employed on an acute care General Internal Medicine unit at an inner city hospital within Edmonton. However, it became apparent throughout the work within the academic collaboration that all parties must be interested in a relationship triad wherein hierarchical power structures are shed or mitigated. This investment is crucial for co-creating and promoting opportunities for self-reflection, learning, and new meaning for all parties involved. These types of relationships are difficult to replicate due to the power-dense structures of acute care services; my goals and proposed outcomes as a novice clinical practitioner presented as too lofty for such setting at this time.

Another main outcome of the project became that of encouraging scholarship of the co-researchers, as well as "planting the seed" for those novice nursing students moving towards the latter half of their undergraduate degree program. A commitment to mentorship which focuses on scholarship reflects a student-centeredness that considers the long-term development needs of the novice Registered Nurse who might be interested in pursuing graduate studies. MacEwan University is an undergraduate educational institution whose mandate is primarily teaching and within the nursing program; there is no particular structure which nurtures the development of scholarship outside the expectations of program completion. 
As such, it is left to MacEwan faculty to informally connect with and inspire students to conceive of themselves pursuing both opportunities for publishing and presentations as well as graduate studies. This provides an opportunity for projects such as this one which allows students to expand beyond curriculum based learning to the pursuit of collaborative scholarship.

\subsubsection{Faculty (Colleen)}

Sustaining a practice of nursing education grounded in caring is not without difficulties. There are many external factors which challenge the educator's ability to substantiate the necessity of grounding the curriculum or an individual course from a caring science perspective. Caring as a concept has been difficult to define, capture, and value within a quantifiable worldview. Employers value the importance of psychomotor and cognitive skills in future graduates which influences the development of a nursing curriculum; ${ }^{[20]}$ however, this perspective is often times in direct opposition to what patients' value and need. ${ }^{[21]}$ This value is often extended into the world of nursing education where curriculum may reflect limited theory and/or opportunity to demonstrate actions reflective of caring sciences. ${ }^{[9,22]}$ So why is a caring science paradigm necessary for this author? My practice has been grounded in a caring science paradigm since my initial introduction at the 2005 International Association for $\mathrm{Hu}$ man Caring (IAHC) annual conference. Members of IAHC believe, "Caring is the essence of nursing and the moral imperative which guides nursing praxis (education, practice and research)"; $;{ }^{[23]}$ providing structure and forum to disseminate knowledge to ensure human dignity. I became familiar with a body of caring knowledge (Boykin, Gadow, Halldórsdóttir, Leininger, Ray, Roach, Sumner, Turkel, Watson, and Wolf) which provided me with answers to a few of my questions in my role as a nurse educator.

\section{What knowledge is necessary to mature into an educator who is not only able to disseminate "best practice" but ultimately makes a difference in her student's lives?}

In my role as a bedside nurse, in an acute care cardiology unit, I was aware of the importance of including best practice (the truths about knowledge) in my nursing interventions and this belief transferred to my role as a nurse educator. Realizing that knowledge for knowledge sake was not enough to make a difference I began to read extensively outside of the medical-surgical disease processes I was charged to disseminate to my students. I became aware that a key component of nursing practice was a relational way of being; understanding this concept from an ontological perspective became vital. "What is the nature of being in relationship with my students?" This was answered when I attended the IAHC conference and heard from the speakers about the necessity of grounding nursing in a caring "way of being". Although this answered my question for my academic purpose I was still struggling to find balance.

\section{How do I sustain a collaborative relationship for learn- ing to balance out my professional and personal needs?}

As a novice educator I believed I needed to keep my professional and personal lives separate. As my caring journey evolved I realized that this separation caused an abyss to develop in the expression of my humanity as I struggled to ensure a dichotomy existed between the two worlds. I came to understand that caring is not only the essence of nursing practice but is the essence which provides the authentic nature of our humanity. Therefore, who I am personally influences who I am professionally and vice versa. Awareness of the importance of recognizing the need to mesh these two worlds helps me to see that my purpose is to live my life, both personally and professionally, as authentically as possible to create a caring practice environment which includes the personal side of my being. A caring practice environment was actualized through the development of collaborative learning relationships between faculty and nursing students which nurtures both the professional and personal aspects of who I am. This collaboration bridges the abyss between learners, offering the opportunity to integrate best practice, clinical institution's expectations, as well as the needs of current nursing students. This opportunity facilitated my development as a caring practitioner by incorporating multiple perspectives thus co-creating meaning in a culture of caring. Fostering a culture of caring, where we are able to express our humanity, is paramount hence ensuring an environment where students and faculty may reach their full potential as human beings.

Why is it important to create a culture of healing and caring in nursing?

I have come to believe that the embodiment of caring knowledge provides me an ethical, epistemological, and ontological perspective to truly make a difference in my student's academic and personal lives, for nursing education, as well as my own development. Understanding how we know what is true (epistemological), how we come to know what is important (ontological), and the nature of relationships (ethical) all inform and confirm the necessity of a caring science approach in nursing education and thus practice. My own journey of caring positively influences my professional development as an intentional nurse educator who embodies a relational way of being. Living as a caring nurse educator is a journey of becoming and being; not a destination. I am open to learning and sharing my student's journeys which ultimately creates positive actions which promote caring and 
healing in myself, others, and hopefully in the profession of nursing.

\section{Discussion}

Journeying with another has both advantages and challenges which can become more apparent in a relationship that has no defined destination. Discerning the process of journeying is vital to ensure growth for all those involved beyond the outcomes which may have been realized. The following insights provide the lived experience of being in relationship from an undergraduate nursing student and faculty member's perspective as they designed an IAC.

\subsection{Why was the formation of this innovative academic collaboration imperative?}

Meredith (M): Transitioning from an undergraduate nursing student to a novice clinical practitioner feels much like leaving home for the first time. There is uncertainty about the future, a certain solitude that one must expect, and some alienation from the previous way of being recognizing that practice will differ from learning. Having the ability to build a significant connection with a mentor faculty member prior to launching into the clinical field maintains a connection to theoretical practice and the idealized view of nursing that buffers against cynicism and burnout in the first year. The IAC also provided hope for future work and development as a novice academic, an opportunity that was not presented or developed elsewhere. The pursuit of intellectual stimulation is easily attended to within a university setting but is not prioritized in the same manner within clinical practice. Participation in this project met these varied needs and provided hope for the future for all parties involved.

Colleen $(\mathrm{C})$ : The formation of this collaboration truly reflects a student-centered approach; providing participation and contributions from those involved and affected during the learning experience. The development of nursing curriculum is influenced by trends and issues in healthcare, local employers, and the expertise and interest of the faculty. These influences may not always capture knowledge, skills, and attributes necessary for the nursing student's clinical practicums and future practice. However, adopting an approach where curriculum development is informed by a currently enrolled undergraduate student's needs from their practice may offer the opportunity to diminish the theorypractice rift. Personally, this approach provides an environment in which to establish a caring community, as context, to foster caring connections between student and faculty; a way to sustain my own journey of caring while facilitating growth (ethical, epistemological, and ontological perspectives) for the student. As this was an innovative way of approaching nursing education - there was much to learn from everyone involved in the process.

\subsection{What did you expect to acquire from this collabora- tion?}

M: My expectations grew over time as the collaboration advanced. Initially, I was hoping to maintain the relationship and connection between myself and my mentor, Colleen. As the project developed and as my understanding of myself and my own abilities evolved, I began to hope that this type of work might translate into a plan for me for future academic studies. I also began to develop a desire to evolve my relationship from that of mentor-mentee to that of caring colleagues; this expectation has been met and exceeded by this experience. I also hoped to have a group of individuals in my life that would encourage mutual engagement in critical self-reflection of and application of caring science into personal practice and professional relationships-this collaboration has allowed this process to continue. An unexpected outcome of this collaboration has been a renewed desire to pursue caring science as a foundational approach for my own future academic studies.

$\mathrm{C}$ : Being in an IAC with a currently enrolled student offered me a realistic and current needs perspective to provide safe, ethical, and competent nursing practice within the course I facilitate. The two co-researchers (undergraduate students) recognized that knowledge on caring, suffering, and healing had not been thoroughly articulated in our current curriculum to inform their practice which left them with many unanswered questions and a lack of confidence. These questions opened a dialogue between student and faculty to discuss their practice while challenging us (nursing faculty) to ensure that future curriculum (theory) informed clinical practice. U1timately, the outcomes from these discussions provided me, as an educator, with constructive feedback to enhance the construction of praxis in the course I was teaching for future students.

Professionally my research interests are in the Scholarship of Teaching and Learning grounded in caring sciences. Therefore, one of the outcomes of the research study was to disseminate knowledge; a poster (provincially) and an oral presentation (internationally) have been realized within this IAC. Scholarly development of the co-researchers was enhanced through the research (proposal writing) and dissemination processes (poster and oral presentation) which were facilitated by the faculty. Mentoring has fostered scholarly inquisitiveness in the co-researchers who have both stated their aspiration is to pursue a Master of Nursing in the future. 
3.3 How will your collaboration, both as process and outcome, influence your future practice?

M: Being on the receiving end of modelled mentorship has changed my perspective on teaching, learning and how to best support others in their own pursuits. In my workplace, I am expected to provide "backup and support" to nursing and other colleagues who might have questions or need assistance. Prior to this experience, I would find myself telling and directing in an autocratic manner. Another seeking help from me might be someone I only encounter once or twice, or never again. Now, I seek to ground my nursing practice in intentional actions, however fleeting the encounter might be. Regardless, it is my intention that any person who comes to me seeking assistance or understanding comes away from our interaction with the sense that I understood and cared about their perspective, that I helped them accomplish their goal/need, and that their presence within our interaction was significant for me. This intentional shift within my own relationships is a direct result of the caring I have received from Colleen and the other partners and has fundamentally altered how I view myself in relation to others. Academically, I now have hope and excitement about the future of caring science in nursing, and a desire to contribute to this through my own academic pursuits. Without participation in the IAC, this would not have been articulated or identified by myself as I had not considered myself capable of such. The IAC has changed my vision of my future in nursing.

$\mathrm{C}$ : As an educator who values relational practice grounded in caring sciences the opportunity to collaborate with students ensured a unique perspective from which nursing education may evolve. Collaboration requires being in relationship with the other; recognizing that each partner has a wealth of knowledge and experience to enhance learning. Continuing to create a caring milieu in which students feel safe sharing their concerns and needs is an important attitude to adopt. Professionally, extending an invitation for collaboration al- lows voice to breathe life into learning (for both student and faculty) which enhances my own development as a nurse educator. Fostering a scholarly inquisitiveness in the current generation of nursing students may ensure a nursing future where positive outcomes for learners and ultimately patients continue to develop.

\section{Conclusion}

Creating and sustaining an innovative academic collaboration requires the adoption an ethical, epistemological, and ontological paradigm to foster a positive co-existence; being in relationship with others. Being able to identify these opportune relationships is a significant challenge and the inability to do so would be a roadblock in developing or moving forward other projects of this nature. Therefore, as educators, we must move beyond adding "caring" to the nursing paradigm and/or introducing caring as an andragogical design; we must embrace caring as the foundational way of knowing, doing, and being for our nursing education and practice to develop and thrive.

"Consistent with the wisdom and vision of Florence Nightingale, nursing is a lifetime journey of caring and healing, seeking to understand and preserve the wholeness of human existence, and to offer compassionate, informed, knowledgeable human caring to society and humankind". ${ }^{[4]}$ Reflection on our practice, seeking to understand, is imperative to enhance the professional development and growth of the caring nurse. Conscious awareness of the relationship of other and one's self, through reflection, may potentiate unlimited possibilities (epistemological) as well as a shared discovery of meaning (ontological) to transcend the relationship (caring in action). Designing learning opportunities (scaffolding metaphorical bridges) to enhance the knowledge and practice of caring sciences may ultimately nourish and sustain the profession of nursing.

\section{REFERENCES}

[1] Roach MS. Caring, the human mode of being: a blueprint for the health professions. 2nd rev. ed. CHA Press. Ottawa: Ontario; 2002.

[2] Sumner J. Reflection and moral maturity in a nurse's caring practice: A critical perspective. Nurs Philos. 2010; 11: 159-169. http: //dx.doi.org/10.1111/j.1466-769X.2010.00445.x

[3] Watson J. Caring Science and Human Caring Theory: transforming personal and professional practices of nursing and healthcare. JHHSA. 2009; 31(4): 466-82. http://dx.doi.org/10.4037/a jcc2011122

[4] McEnroe-Petitte DM. Impact of faculty caring on student retention and success. JTLN. 2011; 6: 80-83. http://dx.doi .org/10.10 $16 / \mathrm{j} \cdot \mathrm{teln} \cdot 2010 \cdot 12.005$
[5] Murphy F, Jones S, Edwards M, et al. The impact of nurse education on the caring behaviours of nursing students. Nurs Educ Today. 2009; 29(2): 254-64. http://dx.doi.org/10.1016/j.nedt. 2008.0 8.016

[6] Stein S, Farmer S. Connotative learning: The trainer's guide to learning theories and their practical application to training design. International Association for Continuing Education and Training. McLean: VA; 2004. 118p.

[7] Tsang AKL. Online reflective group discussion - connecting first year undergraduate students with their third year peers. JoSoTL. 2011; 11(3): 58-74.

[8] Melincavage SM. Student nurses' experiences of anxiety in the clinical setting. Nurs Educ Today. 2011; 31(8): 785-789. http: 
//dx.doi.org/10.1016/j.nedt.2011.05.007

[9] Hagedorn MIE. Caring practices in the 21st century: The emerging role of nurse practitioners. Topics in APN eJournal. 2004; 4(4). Available from: http://www.medscape.com/nursingejournal

[10] Hills M, Watson J. Caring science: curriculum revolutions and detours along the way. In, Creating a caring science curriculum: an emancipatory pedagogy for nursing. Spring Publishing Company \& Watson Caring Science Institute. New York: NY; 2011.

[11] Abdous M, Facer BR, Yen C. Academic effectiveness of podcasting: a comparative study of integrated versus supplemental use of podcasting in second language classes. Comput \& Educ. 2012; 58 : 43-52.

[12] Fernandez V, Simo P, Sallan JM. Podcasting: A new technological tool to facilitate good practice in higher education. Comput \& Educ. 2009; 53: 385-392. http://dx.doi.org/10.1016/j.compedu .2009 .02 .014

[13] Adams J, Gilman B. Students take the professor home. Nurse Educ Pract. 2009; 23(6): 282-285.

[14] Scheckel MM, Ironside PM. Cultivating interpretive thinking through enacting narrative pedagogy. Nurs Outlook. 2006; 54: 159-165. http://dx.doi.org/10.1016/j.outlook.2006.02.002

[15] Dutra D. Implementation of case studies in undergraduate didactic nursing courses: a qualitative study. BioMed Centre Nursing. 2013; 12: 15. http://dx.doi.org/10.1186/1472-6955-12-15
[16] Kaakinen J, Arwood E. Systematic review of nursing simulation literature for use of learning theory. IJNES. 2009; 6(1): 16. http: //dx.doi.org/10.2202/1548-923X.1688

[17] Medley CF, Horne C. Using simulation technology for undergraduate nursing education. Journal of Nurs Educ. 2005; 44(1): 31-34 PMid:15673172.

[18] Wood PJ. Historical imagination, narrative learning and nursing practice: graduate nursing students' reader-responses to a nurse's storytelling from the past. Nurs Educ Prac. 2014; 1-6. http://dx .doi.org/10.1016/j.nepr.2014.05.001

[19] Brown LP. Revisiting our roots: caring in nursing curriculum design Nurs Educ Prac. 2011; 11: 360-364.

[20] Evans RJ, Donnelly GW. A model to describe the relationship between knowledge, skill, and judgment in nursing practice. Nurs Forum. 2006; 41(4): 150-157. PMid:17076797. http://dx.doi .org /10.1111/j.1744-6198.2006.00053.x

[21] Halldorsdottir S. The dynamics of the nurse-patient relationship: introduction of a synthesized theory from the patient's perspective. Scand J Caring Sci. 2008; 22(4): 643-652. http://dx.doi.org/1 $0.1111 / j .1471-6712.2007 .00568 . x$

[22] Griffiths J. A caring professional attitude: what service users and carers seek in graduate nurses and the challenge for educators. Nurse Educ Today. 2012; 32(2): 121 -127. http://dx.doi.org/10.10 $16 / \mathrm{j}$.nedt . 2011.06 .005

[23] IAHC vision. 2014. Available from: http: //www .humancaring. org/aboutus/ 